\title{
ANALISIS EKONOMI PADA PERKUATAN RUMAH GUNA PENGURANGAN DAMPAK GEMPA BUMI
}

\author{
${ }^{1}$ Mohamad F.N. Aulady \\ ${ }^{2}$ Felicia T. Nuciferani \\ ${ }^{3}$ Dyan Eka Nurhayati \\ ${ }^{4}$ Adi A. Pratama \\ ${ }^{1}$ Jurusan Teknik Sipil, Institut Teknologi Adhi Tama Surabaya, \\ mohamadaulady@itats.ac.id \\ ${ }^{2}$ Jurusan Teknik Sipil, Institut Teknologi Adhi Tama Surabaya \\ felicia@itats.ac.id \\ ${ }^{3}$ Jurusan Teknik Sipil, Institut Teknologi Adhi Tama Surabaya \\ dyaneka@itats.ac.id \\ ${ }^{4}$ Jurusan Teknik Sipil, Institut Teknologi Adhi Tama Surabaya \\ adianugrahpratama11@gmail.com
}

\begin{abstract}
ABSTRAK
Indonesia berada pada "Ring of Fire" yang merupakan rangkaian gunung berapi aktif serta terletak pada empat lempeng utama yaitu lempeng Eurasia, lempeng India-Australia, lempeng Laut Filipina dan lempeng Pasifik mengakibatkan timbulnya sesar baru di daerah Surabaya yaitu Sesar Kendeng dan Sesar Waru. Hal ini berpotensi menyebabkan gempa bumi maka masyarakat perlu melakukan tindakan pencegahan untuk mengurangi dampak kerugian yang timbul. Tujuan penelitian yaitu mengaplikasikan metode retrofitting pada bangunan rumah tipe 42/70 disertai dengan analisis cost benefit analysis. Hasil penelitian menyajikan bahwa tingkat kerusakan rumah tanpa dilakukan retrofitting yaitu sebesar 64,42\% dengan total kerugian mencapai Rp. 165.471.763,35. Pada saat retrofitting diaplikasikan dengan metode kombinasi penambahan balok dan kolom yang dibantu aplikasi software maka hasil struktur bangunan rumah lebih tahan terhadap gempa dan tidak terjadi kerusakan pada bangunan disertai biaya retrofitting mencapai Rp. 10.551.814,65. Hasil dari analisis cost benefit analysis yang melakukan perbandingan antara biaya perbaikan atau retrofitting menjadi harga yang lebih efisien bila dibandingkan dengan harga kerusakan yang mencapai Rp 165.471.763,35
\end{abstract}

Kata Kunci : Gempa Bumi, Retrofitting, Cost Benefit Analysis

\section{ABSTRACT}

Indonesia is located on the "Ring of Fire" which is a series of active volcanoes and is located on four main plates, namely the Eurasian plate, the India-Australia plate, the Philippine Sea plate and the Pacific plate, resulting in the emergence of new faults in the Surabaya area, namely the Kendeng Fault and the Waru Fault. 
This has the potential to cause an earthquake, so people need to take preventive measures to reduce the impact of losses that arise. The purpose of this research is to apply the retrofitting method to the house building type 42/70 accompanied by a cost benefit analysis. The results showed that the level of damage to houses without retrofitting was $64.42 \%$ with a total loss of Rp. 165,471,763.35. When retrofitting is applied with the combined method of adding beams and columns assisted by software applications, the results of the house structure are more resistant to earthquakes and there is no damage to the building with retrofitting costs reaching $R p$. 10,551,814.65. The result of the cost benefit analysis that compares the cost of repairs or retrofitting becomes a more efficient price when compared to the damage price which reaches Rp. 165,471,763.35

Keywords: Earthquake, Retrofitting, Cost Benefit Analysis

\section{PENDAHULUAN}

Gempa bumi kerap terjadi di wilayah indonesia. Pada tahun 2020 BMKG mencatat telah terjadi gempa bumi sebanyak 224 kali dengan kekuatan lebih dari 5.0 magnitudo. Wilayah Indonesia yang berada pada "Ring of Fire" yang merupakan rangkaian gunung berapi aktif di dunia (Irsyam et al., 2017), serta terletak pada empat lempeng utama bumi yaitu lempeng Eurasia, lempeng IndiaAustralia, lempeng Laut Filipina dan lempeng Pasifik. (Murtianto, 2016).

Pada penelitian tahun 2017 menyatakan bahwa aktivitas tektonik yang terjadi terus menerus mengakibatkan timbulnya sesar aktif baru yang melewati Kota Surabaya yaitu Sesar Kendeng dan Sesar Waru serta berpotensi menyebabkan gempa bumi. Jumlah penduduk Surabaya 2,87 juta jiwa yang dapat diartikan bahwa jumlah penduduk berbanding lurus dengan kepadatan perumahan di Surabaya. Apabila terjadi gempa bumi maka rawan mengalami kerusakan parah serta memakan korban jiwa. (Widodo, 2017).

Pada awal penelitian terkait pengetahuan tentang potensi gempa bumi di wilayah Kutisari sebanyak 35 responden menyatakan bahwa mereka mengetahui potensi gempa bumi tersebut. Maka diperlukan upaya perbaikan bangunan rumah yaitu menggunakan metode retrofitting. Upaya retrofitting juga digunakan sebagai tindakan guna meminimalisir kerugian serta korban jiwa. 
JURNAL KACAPURI

JURNAL KEILMUAN TEKNIK SIPIL

Volume 4 Nomor 2 Edisi Desember 2021

Tujuan penelitian yaitu memprediksi potensi kerugian dari kerusakan bangunan yang diakibatkan oleh gempa dan total biaya untuk melakukan perbaikan / perkuatan rumah.

\section{TINJAUAN PUSTAKA}

\section{Gempa Bumi}

Getaran asli dari dalam bumi, bermula dari dalam bumi menuju ke permukaan bumu sehingga berakibat pada rekahan bumi pecah dan bergeser dengan keras (Nur, 2010). Gempa memiliki ciri khas, beberapa diantaranya yaitu tidak dapat dicegah, peristiwa yang terjadi secara mendadak, waktu - lokasi - kekuatan terjadinya tidak dapat diperkirakan secara akurat. Bencana gempa bumi tidak dapat dicegah tetapi dapat diupayakan untuk meminimalisir dampaknya maka ada dua metode prediksi gempa bumi yaitu :

1. Prediksi waktu pendek - memprediksi jangka waktu antara fore shock dan main shock tetapi pada kenyataannya banyak yang tidak berhasil.

2. Prediksi waktu panjang - mempelajari interval gempa bumi sesuai siklusnya.

\section{Penyebab Gempa Bumi}

Penyebab gempa bumi terdiri dari tiga yaitu :

1. Gempa tektonik - gempa dengan kekuatan terbesar dan diakibatkan karena patahan lempeng bumi, sehingga saat terjadinya mencakup wilayah yang luas.

2. Gempa Vulkanik - gempa bumi yang terjadi akibat letusan gunung berapi.

3. Gempa Runtuhan - gempa bumi yang terjadi akibat runtuhnya atap goa yang terdapat pada lapisan litosfer, sehingga kekuatannya relatif rendah.

Berdasarkan ketiga penyebab gempa bumi ini maka berpotensi akan mengakibatkan timbulnya korban jiwa mulai dari tertimpa reruntuhan maupun rusaknya bangunan rumah tinggal mereka. (Sungkawa, 2016)

\section{Retrofitting}

Metode perbaikan atau perkuatan disebut retrofitting. Metode perbaikan memiliki pengertian yaitu suatu tindakan dalam modifikasi struktur yang telah mengalamani kerusakan yang dilakukan pada seluruh atau sebagian bangunan 
guna mengembalikan stabilitas struktur pada kondisi semula. Menurut Boen,2010 terdapat tiga metode retrofitting yaitu :

1. Memperbesar dimensi dan menambah jumlah tulangan pada bagian struktur utama bangunan yang mengalami kerusakan

2. Menambah jumlah tulangan dan sengkang diluar kolom

\section{Cost Benefit Analysis}

Cost benefit analysis merupakan metode yang digunakan untuk melakukan evaluasi manajemen. Analisis inipun juga dapat digunakan untuk mengevaluasi beberapa alternatif sumber daya atau program yang memiliki manfaat lebih baik daripada alternatif lainnya. (Probandari,2007)

Pada penelitian ini Cost benefit analysis digunakan untuk mengukur biaya serta manfaat maupun dampak pada hasil retrofitting bangunan rumah. Analisis sistematis yang digunakan untuk menghitung serta membandingkan biaya dan manfaat dari retrofitting perkuatan tahan gempa.

\section{METODOLOGI PENELITIAN}

\section{Jenis dan Sumber Data}

Metode penelitian menggunakan metode survei dan analisis perhitungan struktur bangunan. Data primer terdiri dari kuisioner, survey lokasi dan tipe bangunan sedangkan data sekunder berupa harga satuan pokok kegiatan (HSPK) Kota Surabaya serta desain spektra daerah Surabaya.

Data primer yang berupa survei lokasi untuk mendapatkan dokumentasi dan kondisi rumah. Hasil wawancara digunakan untuk mengetahui kesiapan masyarakat terkait potensi terjadi gempa bumi.

Data sekunder berupa HSPK digunakan untuk menentukan biaya pada tiap pekerjaan. Desain spektra digunakan untuk analisis pembebanan struktur pada rumah type $42 / 70$.

\section{Tahapan Penelitian}

Tahap awal penelitian yaitu melakukan observasi guna mendapatkan data struktur bangunan rumah dan data harga rumah. Tahapan kedua penelitian, data struktur 
bangunan akan digunakan untuk pengolahan data retrofitting sedangkan data harga rumah akan digunakan untuk perhitungan cost benefit analysis.

Pada saat survei perumahan untuk design review pada rumah type 42/70. Pemodelan pada rumah tersebut dengan mensimulasikan beban struktur bangunan sesuai Standar Nasional Indonesia (SNI, 2019) dan response spectrume.

Pada tahap ketiga dilakukan perhitungan tingkat prosentase kerusakan. Berdasarkan hasil pada tahap ketiga peneliti memilih metode perbaikan atau retrofitting menggunakan penambahan balok dan kolom sebagai perkuatan rumah type $42 / 70$, tahapan inipun menjadi tahapan yang keempat.

Hasil pada tahapan keempat akan digunakan untuk menghitung total kerugian pada rumah yang terdampak bencana. Tahapan kelima yaitu perhitungan analisis biaya retrofitting untuk mengetahui besaran cost benefit analysisnya serta benefit cost ratio.

\section{HASIL DAN PEMBAHASAN}

\section{Data Gempa}

Berdasarkan data Spektra Indonesia dengan jenis tanah diwilayah Surabaya yaitu tanah lunak maka grafik spektrum respon desain dapat dilihat pada gambar 1.

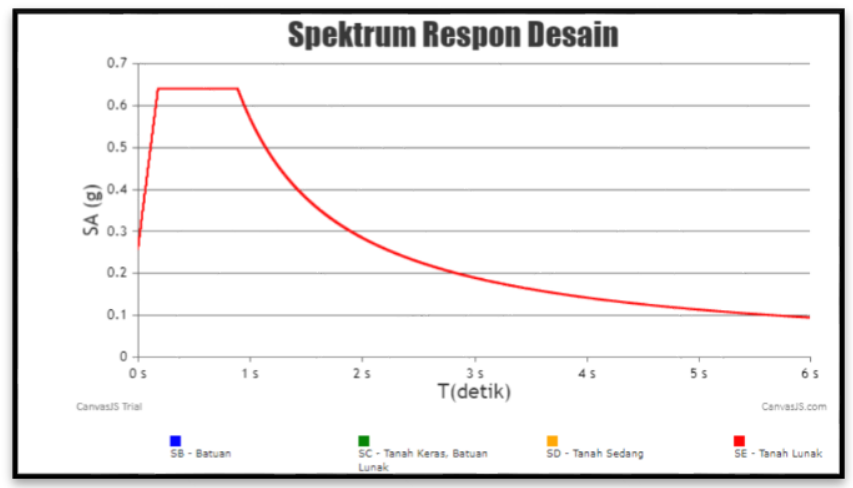

Sumber : http://rsa.ciptakarya.pu.go.id/, 2021

Gambar 1. Grafik Spektrum Respon Desain

\section{Analisis Harga Bangunan Rumah}

Perhitungan harga satuan untuk rumah type 42/70 berdasarkan pada desain gambar rumah untuk mengetahui volume pekerjaan, serta data HSPK Kota 
JURNAL KACAPURI

JURNAL KEILMUAN TEKNIK SIPIL

Volume 4 Nomor 2 Edisi Desember 2021

Surabaya untuk analisis perhitungan total harga rumah tersebut. Analisis harga bangunan dapat dilihat pada tabel 1 .

Tabel 1. Analisis Harga Bangunan

\begin{tabular}{|c|c|c|c|c|c|}
\hline No & Uraian Pekerjaan & Volume & Satuan & $\begin{array}{l}\text { Nilai Hspk } \\
\quad \text { (Rp) }\end{array}$ & $\begin{array}{l}\text { Harga } \\
(\mathrm{Rp})\end{array}$ \\
\hline \multirow[t]{3}{*}{1} & \multicolumn{5}{|l|}{ Pekerjaan Persiapan } \\
\hline & $\begin{array}{l}\text { 1.1. Pembersihan lapangan } \\
\text { "Ringan dan Peralatan" }\end{array}$ & 70 & $\mathrm{~m}^{2}$ & $12.250,00$ & $857.500,00$ \\
\hline & $\begin{array}{l}\text { 1.2. Pengukuran dan } \\
\text { pemasangan "Bowplank" }\end{array}$ & 42 & $\mathrm{~m}^{2}$ & $117.209,00$ & $5.304 .375,00$ \\
\hline \multirow[t]{6}{*}{2} & \multicolumn{5}{|l|}{ Pekerjaan Pondasi } \\
\hline & $\begin{array}{l}\text { 2.1. Pekerjaan galian tanah } \\
\text { pondasi }\end{array}$ & 26,88 & $\mathrm{~m}^{3}$ & $120.750,00$ & $3.245 .760,00$ \\
\hline & $\begin{array}{l}\text { 2.2. Pekerjaan pengurugan pasir } \\
\text { bawah pondasi }\end{array}$ & 1,215 & $\mathrm{~m}^{3}$ & $259.500,00$ & $1.542 .319,00$ \\
\hline & $\begin{array}{l}\text { 2.3. Pekerjaan pemasangan } \\
\text { astamping }\end{array}$ & 5,04 & $\mathrm{~m}^{3}$ & $816.500,00$ & $3.541 .768,00$ \\
\hline & $\begin{array}{l}\text { 2.4. Pekerjaan Pemasangan batu } \\
\text { kali }\end{array}$ & 13,44 & $\mathrm{~m}^{3}$ & 1.269 .398 & $8.054 .330,00$ \\
\hline & $\begin{array}{l}\text { 2.5. Pekerjan pengurugan tanah } \\
\text { kembali bekas galian }\end{array}$ & 7,185 & $\mathrm{~m}^{3}$ & 86.500 & $708.435,00$ \\
\hline 3 & \multicolumn{5}{|l|}{ Pekerjaan Beton Bertulang } \\
\hline & $\begin{array}{r}\text { 3.1.Pekerjaan sloof beton } \\
\text { bertulang }+ \text { bekesting }\end{array}$ & 1,515 & $\mathrm{~m}^{3}$ & $6.275 .635,00$ & $9.507 .587,00$ \\
\hline & $\begin{array}{c}\text { 3.2. Pekerjaan kolom beton } \\
\text { bertulang + bekesting }\end{array}$ & 0,936 & $\mathrm{~m}^{3}$ & $6.501 .265,00$ & $6.085 .184,00$ \\
\hline & 3.3.Pekerjaan ring balok & 1,12 & $\mathrm{~m}^{3}$ & $7.619 .290,00$ & $8.533 .605,00$ \\
\hline & 3.4.Pekerjaan balok gewel & 0,315 & $\mathrm{~m}^{3}$ & $7.619 .290,00$ & $2.400 .076,00$ \\
\hline \multirow[t]{3}{*}{4} & \multicolumn{5}{|l|}{ Pekerjaan Dinding } \\
\hline & $\begin{array}{l}\text { 4.1.Pemasangan dinding batu } \\
\text { merah } 1 \mathrm{pc}: 3 \mathrm{pp} \text { tebal } 1 / 2 \\
\text { bata }\end{array}$ & 137,6 & $\mathrm{~m}^{2}$ & $146.121,40$ & $41.219 .318,40$ \\
\hline & $\begin{array}{l}\text { 4.2.Pekerjaan plesteran halus } \\
\text { 1pc: } 3 \text { ps tebal } 1,5 \mathrm{~cm}\end{array}$ & 137,6 & $\mathrm{~m}^{2}$ & $87.844,92$ & $12.488 .714,92$ \\
\hline \multirow[t]{4}{*}{5} & \multicolumn{5}{|l|}{ Pekerjaan Pintu dan Jendela } \\
\hline & $\begin{array}{l}\text { 5.1.Pemasangan kusen pintu } \\
\text { dan jendela kayu Meranti }\end{array}$ & 0,34 & $\mathrm{~m}^{2}$ & $9.466 .400,00$ & $3.218 .576,00$ \\
\hline & $\begin{array}{l}\text { 5.2.Pemasangan daun pintu dan } \\
\text { jendela (kayu kamper) }\end{array}$ & 8,6 & $\mathrm{~m}^{2}$ & $636.600,00$ & $5.474 .760,00$ \\
\hline & 5.3.Pemasangan daun pintu pvc & 1 & $\mathrm{Bh}$ & $477.800,00$ & $477.800,00$ \\
\hline \multirow[t]{5}{*}{6} & \multicolumn{5}{|l|}{ Pekerjaan Atap } \\
\hline & $\begin{array}{l}\text { 6.1.Pemasangan rangka atap } \\
\text { gording }\end{array}$ & 0,28 & $\mathrm{~m}^{3}$ & 10.164 .380 & $2.846 .000,00$ \\
\hline & $\begin{array}{l}\text { 6.2.Pemasangan rangka atap } \\
\text { kaso/usuk }\end{array}$ & 49 & $\mathrm{~m}^{3}$ & $171.403,40$ & 8.398 .766 .60 \\
\hline & $\begin{array}{l}\text { 6.3.Pemasangan rangka atap } \\
\text { reng }\end{array}$ & 86,7 & $\mathrm{~m}^{3}$ & $171.403,40$ & $14.860 .674,78$ \\
\hline & $\begin{array}{l}\text { 6.4.Pemasangan genteng } \\
\text { karang pilang/wisma }\end{array}$ & 47,5 & $\mathrm{~m}^{3}$ & $393.505,00$ & $18.691 .487,50$ \\
\hline \multirow[t]{4}{*}{7} & \multicolumn{5}{|l|}{ Pekerjaan Intstalasi Listrik } \\
\hline & 7.1.Pemasangan stop kontak & 4 & Titik & $42.155,00$ & $168.620,00$ \\
\hline & 7.2.Pemasangan lampu & 6 & Titik & $513.800,00$ & $3.082 .800,00$ \\
\hline & 7.3.Pemasangan saklar ganda & 2 & Titik & $91.555,00$ & $183.110,00$ \\
\hline
\end{tabular}


JURNAL KACAPURI

JURNAL KEILMUAN TEKNIK SIPIL

Volume 4 Nomor 2 Edisi Desember 2021

\begin{tabular}{|c|c|c|c|c|c|}
\hline No & Uraian Pekerjaan & Volume & Satuan & $\begin{array}{l}\text { Nilai Hspk } \\
\quad \text { (Rp) }\end{array}$ & $\begin{array}{c}\text { Harga } \\
(\mathrm{Rp})\end{array}$ \\
\hline & 7.4.Pemasangan saklar tunggal & 2 & Titik & $91.555,00$ & $183.110,00$ \\
\hline \multirow[t]{4}{*}{8} & \multicolumn{5}{|l|}{ Pekerjaan Plafon } \\
\hline & $\begin{array}{l}\text { 8.1.Pemasangan rangka plafon } \\
\text { kayu meranti }\end{array}$ & 185,5 & $\mathrm{~m}$ & $136.254,00$ & $25.275 .117,00$ \\
\hline & $\begin{array}{l}\text { 8.2.Pemasangan plafon gypsum } \\
9 \mathrm{~mm}\end{array}$ & 47,5 & $\mathrm{~m}^{2}$ & $53.500,00$ & $2.541 .250,00$ \\
\hline & 8.3.Pemasangan list plafon & 53 & $\mathrm{~m}$ & $56.564,00$ & $2.997 .892,00$ \\
\hline \multirow[t]{4}{*}{9} & \multicolumn{5}{|l|}{ Pekerjaan Sanitasi } \\
\hline & 9.1.Pemasangan kran air & 3 & $\mathrm{Bh}$ & $80.850,00$ & $242.550,00$ \\
\hline & $\begin{array}{l}\text { 9.2.Pemasangan kloset duduk } \\
\text { porselan }\end{array}$ & 1 & $\mathrm{Bh}$ & $4.322 .936,00$ & $4.322 .936,00$ \\
\hline & 9.3.Pemasangan wastafel & 1 & $\mathrm{Bh}$ & $999.549,00$ & $999.549,00$ \\
\hline \multirow[t]{3}{*}{10} & \multicolumn{5}{|l|}{ Pekerjaan Lantai } \\
\hline & $\begin{array}{l}\text { 10.1.Pemasangan keramik } \\
40 \times 40 \mathrm{~cm}\end{array}$ & 41,5 & $\mathrm{~m}^{2}$ & $282.027,50$ & $11.704 .121,50$ \\
\hline & $\begin{array}{l}\text { 10.2.Pemasangan keramik } \\
20 \times 20 \mathrm{~cm}\end{array}$ & 8,25 & $\mathrm{~m}^{2}$ & $303.009,90$ & $2.499 .824,90$ \\
\hline 11 & \multicolumn{5}{|l|}{ Pekerjaan finishing } \\
\hline & 11.1.Pekerjaan acian & 137,6 & $\mathrm{~m}^{2}$ & $53.739,50$ & $7.394 .486,50$ \\
\hline & 11.2.Pekerjaan Plamir & 147,5 & & $24.690,00$ & $3.397 .344,00$ \\
\hline & 11.3.Pekerjaan Pengecatan & 147,5 & $\mathrm{~m}^{2}$ & $32.903,00$ & $5.915 .562,00$ \\
\hline & 11.4.Pekerjaan kusen & 0,34 & $\mathrm{~m}^{2}$ & $70.999,00$ & $241.397,00$ \\
\hline \multicolumn{5}{|c|}{ Total Harga Bangunan } & $256.863 .960,50$ \\
\hline
\end{tabular}

Sumber : Hasil Olahan Peneliti, 2021

\section{Analisis Retrofitting Beserta Cost Benefit Analysis}

Analisis retrofitting digunakan untuk mengetahui rumah type 42/70 yang tahan terhadap bencana gempa bumi, serta meminimalisir kerugian terhadap material dan korban jiwa. Gambar 2 menunjukkan perbedaan rumah yang tidak dilakukan perbaikan / retrofitting dan rumah yang sudah dilakukan perbaikan.

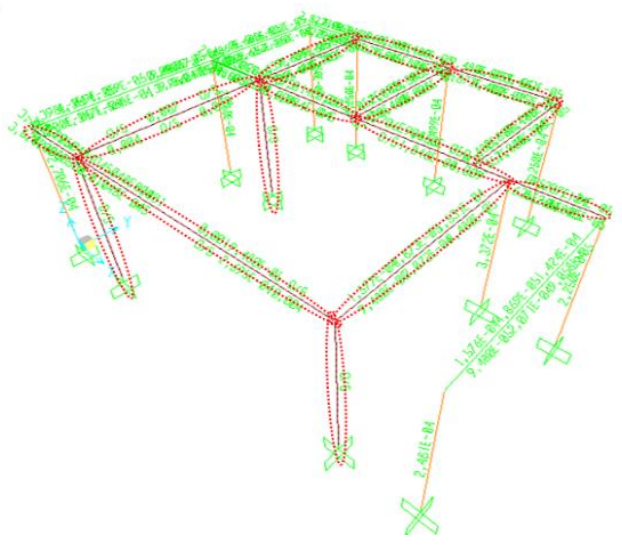

(a)

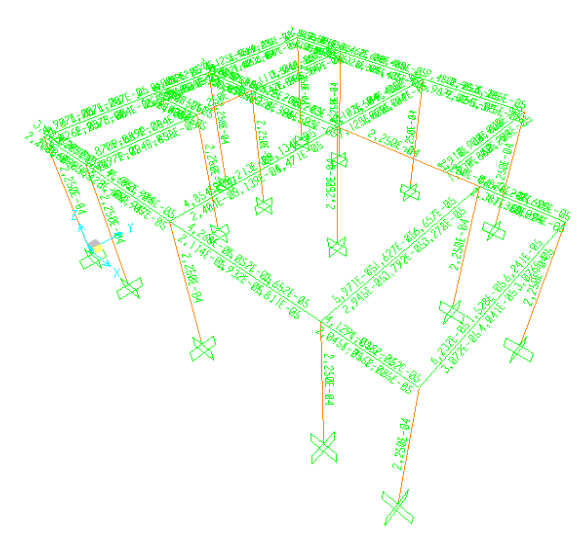

(b)

Gambar 2. (a) sebelum dilakukan retrofitting.(b) setelah dilakukan retrofitting. 
Pada gambar 2.(a) terlihat limabelas titik struktur mengalami kegagalan struktur akibat terjadinya benca gempa bumi maka pada gambar 2.(b) merupakan pemodelan struktur yang sudah dilakukan retrofitting yang tidak mengalami kegagalan struktur. Berdasarkan hasil inilah maka dilakukan analisis cost benefit analysis untuk mengetahui prosentase kerusakannya serta biaya perbaikannya.

Tabel 2. Rekapitulasi Hasil analisis penelitian adalah sebagai berikut.

\begin{tabular}{|c|c|c|c|c|c|}
\hline No & $\begin{array}{c}\text { Keterangan } \\
\text { Analisis }\end{array}$ & $\begin{array}{c}\text { Presentase } \\
\text { Kerusakan }\end{array}$ & $\begin{array}{c}\text { Biaya } \\
\text { Retrofitting } \\
\text { (Rp.) }\end{array}$ & $\begin{array}{c}\text { Total Kerugian } \\
\text { (Rp.) }\end{array}$ & $\begin{array}{c}\text { Cost Benefit } \\
\text { Ratio }\end{array}$ \\
\hline 1 & $\begin{array}{c}\text { rumah sebelum } \\
\text { dilakukan } \\
\text { perkuatan }\end{array}$ & $64,42 \%$ & - & $165.471 .763,35$ & - \\
\hline 2 & $\begin{array}{c}\text { rumah setelah } \\
\text { dilakukan } \\
\text { perkuatan }\end{array}$ & $0 \%$ & $10.551 .814,65$ & $0,-$ & $24,33>1$ \\
\hline
\end{tabular}

Sumber : Hasil Olahan Peneliti, 2021

Harga bangunan rumah type 42/70 mencapai Rp 256.863.960,50 dari harga tersebut apabila tidak dilakukan retrofitting maka mengalami kerusakan yang mencapai 64,42 \% dengan harga kerugian sebesar Rp 165.471.763,35. Metode perkuatan/retrofitting menggunakan penambahan balok dan kolom berfungsi untuk meminimalisir dari dampak gempa sehingga menghasilkan perhitungan cost benefit analysis dengan prosentase kerusakan $0 \%$ dan biaya perbaikan sebesar Rp 10.551.814,65. Harga retrofitting tersebut terjangkau serta efisien apabila dibandingkan dengan tidak dilakukannya retrofitting.

\section{PENUTUP}

\section{Kesimpulan}

Keuntungan yang didapatkan dengan dilakukannya retrofitting menggunakan metode penambahan balok dan kolom menjadikan rumah tersebut lebih tahan dan kuat saat terjadi gempa bumi. Kerugian serta kerusakan bangunan saat sebelum dilakukan retrofitting dengan tingkat kerusakan bangunan sebesar 64,42 \% dengan total kerugian mencapai Rp. 165.471.763,35.

\section{Saran}


Penelitian ini dapat dijadikan acuan awal untuk meminimalkan terjadinya gempa bumi di Surabaya yang diakibatkan karena munculnya dua sesar aktif baru yang melewati Kota Surabaya yaitu Sesar Kendeng dan Sesar Waru.

Penelitian retrofitting pada lokasi yang rawan terjadi gempa bumi dengan jenis pondasi batukali pada simulasi pemodelannya dapat menggunakan tumpuan merata.

\section{DAFTAR PUSTAKA}

Badan meteorologi klimatologi dan geofisika. 2020. Peta Seismisitas Indonesia,(online), https://www.bmkg.go.id/seismologi-teknik/Di akses 25 november, 2020.

Badan Standarisasi Nasional. 2019. Tata Cara Perencanaan Ketahanan Gempa Untuk Struktur Bangunan Gedung dan Non Gedung.1726. Badan Standarisasi Nasional. Jakarta.

Boen,Teddy. 2010. Cara Memperbaiki Bangunan Sederhana Yang Rusak Akibat Gempa Bumi

Desain Spektra Indonesia. 2021. Desain Spektra Indonesia 2021. Direktorat Bina Teknik Permukiman Dan Perumahan, Direktorat Jendral Cipta Karya, Kementrian Pekerjaan Umum Dan Perumahan Rakyat, (online), http://rsa.ciptakarya.pu.go.id/, 2021. Di akses 13 April, 2021.

Irsyam, M. , Lutfi, R. 2017. Peta sumber dan bahaya gempa Indonesia tahun 2017. Bandung: Pusat Penelitian dan Pengembangan Perumahan dan Permukiman, Badan Penelitian dan Pengembangan, Kementerian Pekerjaan Umum, (online),

https://www.bnpb.go.id/uploads/24/seminar/PemutahiranSumberdanPetaGempaIn donesia. Di akses 22 september, 2020.

Murtianto, Hendro. 2016. Potensi Kerusakan Gempa Bumi Akibat Pergerakan Patahan Sumatera Di Sumatera Barat dan Sekitarnya. Jurnal Geografi Gea.

Nur, Arief Mustofa. 2010. Gempa Bumi, Tsunami, dan Mitigasinya. Jurnal Geografi. Balai Informasi dan Konservasi Kebumian karangsambung - LIPI, Kebumen.

Sungkawa, Dadang. 2016. Dampak Gempa bumi Terhadap Lingkungan Hidup. Jurnal Geografi Gea

Probandari, Ari. 2007. Cost Effectiveness Analysis Dalam Penentuan Kebijakan kesehatan : Sekedar Konsep Atau Aplikatif ?. Jurnal Manajemen Pelayanan Kesehatan. 
JURNAL KACAPURI

JURNAL KEILMUAN TEKNIK SIPIL

Volume 4 Nomor 2 Edisi Desember 2021

Widodo, Amien. 2017. Identifikasi Percepatan Tanah Maksimum (PGA) dan

Kerentanan Tanah Menggunakan Metode Mikrotremor Jalur Sesar Kendeng. Jurnal Geosaintek 